ARTICLE

https://doi.org/10.1038/s41467-019-12853-8

\title{
Collective excitation of plasmon-coupled Au-nanochain boosts photocatalytic hydrogen evolution of semiconductor
}

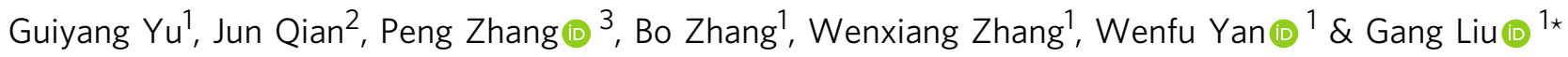

Localized surface plasmon resonance (LSPR) offers a valuable opportunity to improve the efficiency of photocatalysts. However, plasmonic enhancement of photoconversion is still limited, as most of metal-semiconductor building blocks depend on LSPR contribution of isolated metal nanoparticles. In this contribution, the concept of collective excitation of embedded metal nanoparticles is demonstrated as an effective strategy to enhance the utilization of plasmonic energy. The contribution of Au-nanochain to the enhancement of photoconversion is 3.5 times increase in comparison with that of conventional isolated $\mathrm{Au}$ nanoparticles. Experimental characterization and theoretical simulation show that strongly coupled plasmonic nanostructure of Au-nanochain give rise to highly intensive electromagnetic field. The enhanced strength of electromagnetic field essentially boosts the formation rate of electron-hole pair in semiconductor, and ultimately improves photocatalytic hydrogen evolution activity of semiconductor photocatalysts. The concept of embedded coupled-metal nanostructure represents a promising strategy for the rational design of highperformance photocatalysts.

\footnotetext{
${ }^{1}$ State Key Laboratory of Inorganic Synthesis and Preparative Chemistry, College of Chemistry, Jilin University, 2699 Qianjin Road, 130012 Changchun, China. ${ }^{2}$ School of Physics, Nankai University, 300071 Tianjin, China. ${ }^{3}$ Department of Chemistry, Dalhousie University, 6274 Coburg Road, Halifax B3H4R2, Canada. *email: Igang@jlu.edu.cn
} 
E nhancing the efficiency of semiconductor photocatalysts is of paramount importance for realizing more efficient conversion of solar energy in artificial photosynthesis ${ }^{1-7}$. Integrating a plasmonic metal nanostructure with a semiconductor has been found as a promising alternative to improve the efficiency of conventional architectures ${ }^{8-11}$. The enhanced photoreactivity is attributed to the localized surface plasmon resonances (LSPRs) of plasmonic metal, in which confined free electrons oscillate with the same frequency as the incident radiation, giving rise to intense, highly localized electromagnetic fields ${ }^{12-16}$. However, plasmonic enhancement of photoconversion is still limited, far from reaching the theoretical maximum efficiency of plasmonic metal-semiconductor ${ }^{17}$. To advance this emerging method, some basic problems, such as the architectures and fabrication strategies of plasmon building blocks, need to be carefully reconsidered.

Three major energy transfer mechanisms between plasmonic metals and semiconductors have been proposed in the past decade: light scattering, hot electron injection, and plasmon-induced resonance energy transfer ${ }^{10,18-20}$. A big challenge is how to design a plasmonic metal-semiconductor heterostructure for offering great possibility in enabling above three major plasmonic energy transfer mechanisms. Primarily, the proximity of semiconductor to plasmonic metal should be one of important factors to improve the energy transfer. It is not only because the plasmonic hot electrons need an interfacial transfer through overcoming a Schottky barrier, but also the distance could significantly lower the plasmon-induced resonance energy transfer from the metal to the semiconductor ${ }^{12,21-23}$. The localized electromagnetic fields of plasmonic metal are spatially non-homogenous. The highest intensity is at the surface of the plasmonic metal and decreasing exponentially distance from the surface ${ }^{24-26}$. Much closer to the plasmonic metal, more electromagnetic fields can be captured. However, most of current researches based on a nanostructure with isolated metal particles dispersed on semiconductor surface. The proximity of semiconductor to the electromagnetic fields of plasmonic metal is limited for such architectures.

In addition, enhancing the local intensity of plasmon-induced electromagnetic fields is another crucial factor for maximizing efficiency of plasmonic metal-semiconductor. We have known that it partly depends on the competence of particle nature, including the composition, size, and shape ${ }^{27-31}$. While the collective behaviors of dense metal nanoparticles to the plasmonic enhancement is still unclear. Although some physical research show that strongly coupled metallic nanostructures would generate much higher electromagnetic fields at the adjacent spot, what kind of architectures would be effective for the semiconductor photocatalyst systems is still unknown ${ }^{32-34}$. It should be simultaneously considered the spatial arrangement of semiconductor and plasmonic metals. It would significantly depend on a rational design of plasmonic metal-semiconductor building blocks.

In this contribution, considering both the strength and transfer of plasmonic energy, a plasmonic building block that embedding a strongly plasmon-coupled metal nanostructure is fabricated. Aunanochain (a strongly plasmon-coupled metal nanostructure) is built into $\mathrm{Zn}_{x} \mathrm{Cd}_{1-x} \mathrm{~S}$ semiconductor (denoted as $\mathrm{Au}$ chain@ $\left.\mathrm{Zn}_{x} \mathrm{Cd}_{1-x} \mathrm{~S}, x=0.67\right)$. Visible-light-driven hydrogen evolution rate of $\mathrm{Zn}_{0.67} \mathrm{Cd}_{0.33} \mathrm{~S}$ can be boosted to $16,420 \mu \mathrm{mol} \mathrm{h}{ }^{-1} \mathrm{~g}^{-1}$ by the Au-nanochain. The apparent quantum efficiency can reach $54.6 \%$ at $420 \mathrm{~nm}$. All these results are obtained without additional cocatalysts. The contribution of Au-nanochain to the enhancement of photoconversion is 3.5 times increase in comparison with that of conventional isolated $\mathrm{Au}$ nanoparticles. A systematic investigation is carried out to clarify the dependence of the photocatalytic performance on the spatial arrangement of plasmonic metal in the metal-semiconductor building blocks. Both the theoretical simulation and experimental characterization shows that Au-nanochain could give rise to much higher local electromagnetic field than that of isolated Au nanoparticles when excited by the incident light. It essentially increases the formation of the electron-hole pair on the nearby semiconductors and causes a high reactivity. The concept of embedding coupled-metal nanostructure in semiconductors represents an efficient way to enhance the solar energy conversion efficiency.

\section{Results}

Preparation and structural analysis of Au-nanochaincontaining sample. Au-chain@ $\mathrm{Zn}_{x} \mathrm{Cd}_{1-x} \mathrm{~S}(x=0.67)$ was prepared by a hydrothermal method. Figure 1a illustrates the preparation procedures of the heterostructure from ions. Firstly, $L$-cysteine solution was mixed with $\mathrm{Zn}\left(\mathrm{NO}_{3}\right)_{2}$ or $\mathrm{Cd}\left(\mathrm{NO}_{3}\right)_{2}$ to form the stable complexes of cysteine- $\mathrm{Zn}^{2+} / \mathrm{Cd}^{2+}$. Next, $\mathrm{Au}$ colloids with uniform particle size of $15 \mathrm{~nm}$ was added to the freshly prepared cysteine- $\mathrm{Zn}^{2+} / \mathrm{Cd}^{2+}$ solution under vigorous stirring. Finally, the cysteine- $\mathrm{Zn}^{2+} / \mathrm{Cd}^{2+}$-coupled $\mathrm{Au}$ colloids were transferred into Teflon-lined stainless-steel autoclaves and maintained at $130{ }^{\circ} \mathrm{C}$ for $6 \mathrm{~h}$. The Au colloids were prepared by reducing $\mathrm{HAuCl}_{4}$ with sodium citrate in an aqueous solution (see details in the "Methods" section and Supplementary Figs. 1 and 2). The measured elemental composition of $\mathrm{Zn} / \mathrm{Cd}$ from inductively coupled plasma (ICP) spectroscopy is closely to the concentration of $\mathrm{Zn}^{2+} / \mathrm{Cd}^{2+}$ used during the synthesis. Transmission electron microscopy (TEM) image shows the spatial arrangement of $\mathrm{Au}$ nanoparticles in Au-chain@ $\mathrm{Zn}_{0.67} \mathrm{Cd}_{0.33} \mathrm{~S}$ (Fig. 1b). Au nanoparticles connect with each other forming a chain shape. Some branches can be observed in the image, but all the $\mathrm{Au}$ nanoparticles are closely packed. $\mathrm{Zn}_{0.67} \mathrm{Cd}_{0.33} \mathrm{~S}$ grows around the $\mathrm{Au}$-nanochains and wrapped them completely. No porous structure can be found in the images. High-resolution transmission electron microscopy (HRTEM) image (Fig. 1c), clearly shows the fringe of $0.24 \mathrm{~nm}$, which is ascribed to the face-centered cubic (fcc) $\mathrm{Au}$ (111). While another set of lattices with periodic spacing of $0.31 \mathrm{~nm}$ are assigned to cubic $\mathrm{Zn}_{0.67} \mathrm{Cd}_{0.33} \mathrm{~S}$ (101) lattice planes. Two sets of reflections can be observed in selected area electron diffraction (SAED) patterns (Fig. 1b inset). High-angle annular dark-field (HAADF) image and energy-dispersive X-ray spectroscopy (EDXS) mapping images (Fig. 1d), could also clearly depict the arrangement of Au nanoparticles, while $\mathrm{Zn}, \mathrm{Cd}$, and $\mathrm{S}$ are homogeneously distributed on Au-chain@ $\mathrm{Zn}_{0.67} \mathrm{Cd}_{0.33} \mathrm{~S}$.

Theoretical simulation. Three-dimensional finite difference time domain (FDTD) method is used to simulate the near-field distributions of isolated and coupled nanoparticles (Fig. 1e and Supplementary Figs. 3-5). The total field scattered field (TF/SF) source is used in simulation. The incident wavelength is $520 \mathrm{~nm}$. The grid spacing is $0.5 \mathrm{~nm}$. The radius of gold nanosphere is $7.5 \mathrm{~nm}$. Figure 1e shows the electric field distributions of $\mathrm{Au}$ nanoparticles with different interparticle distances. When distance decrease from 20 to $2 \mathrm{~nm}$, the strength of electromagnetic fields increase at least one order of magnitudes at hot spot area. It demonstrates that Au-nanochain can give rise to highly intense and localized electromagnetic fields when excited by incident light of the appropriate polarization.

Photocatalytic performance. Photocatalytic test of Auchain@ $\mathrm{Zn}_{0.67} \mathrm{Cd}_{0.33} \mathrm{~S}$ under visible light $(\geq 420 \mathrm{~nm})$ gives an activity of $16,420 \mu \mathrm{mol} \mathrm{h}^{-1} \mathrm{~g}^{-1}$ for hydrogen evolution (Fig. 1d). It is about 20 times of commercial CdS $\left(830 \mu \mathrm{mol} \mathrm{h}^{-1} \mathrm{~g}^{-1}\right)$, and 3.3 times of pure $\mathrm{Zn}_{0.67} \mathrm{Cd}_{0.33} \mathrm{~S}\left(5020 \mu \mathrm{mol} \mathrm{h}{ }^{-1} \mathrm{~g}^{-1}\right)$ prepared with the same method as Au-chain@ $\mathrm{Zn}_{0.67} \mathrm{Cd}_{0.33} \mathrm{~S}$. It should be 
a
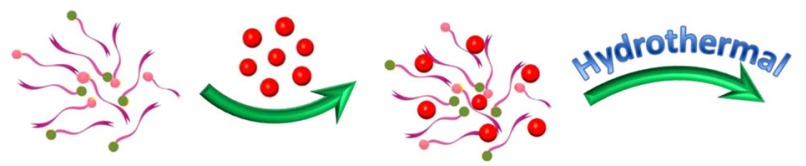

Au-chain@ $\mathrm{Zn}_{0.67} \mathrm{Cd}_{0.33} \mathrm{~S}$

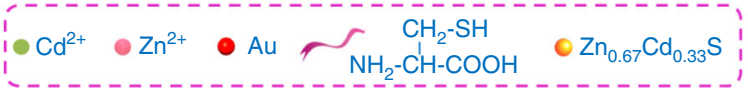

b

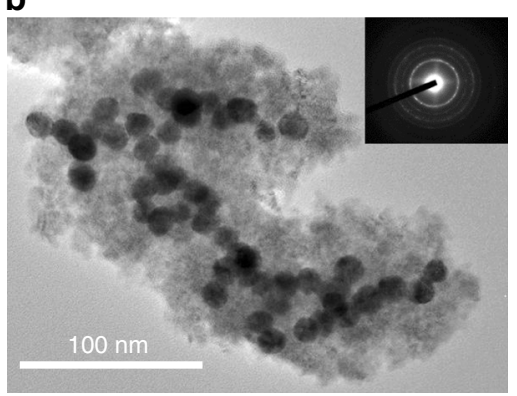

C

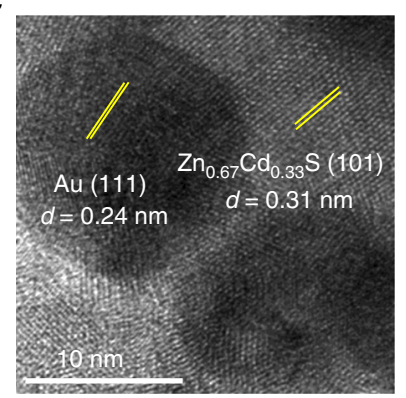

d

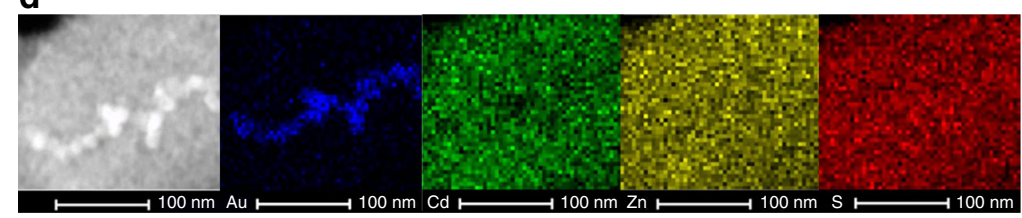

e
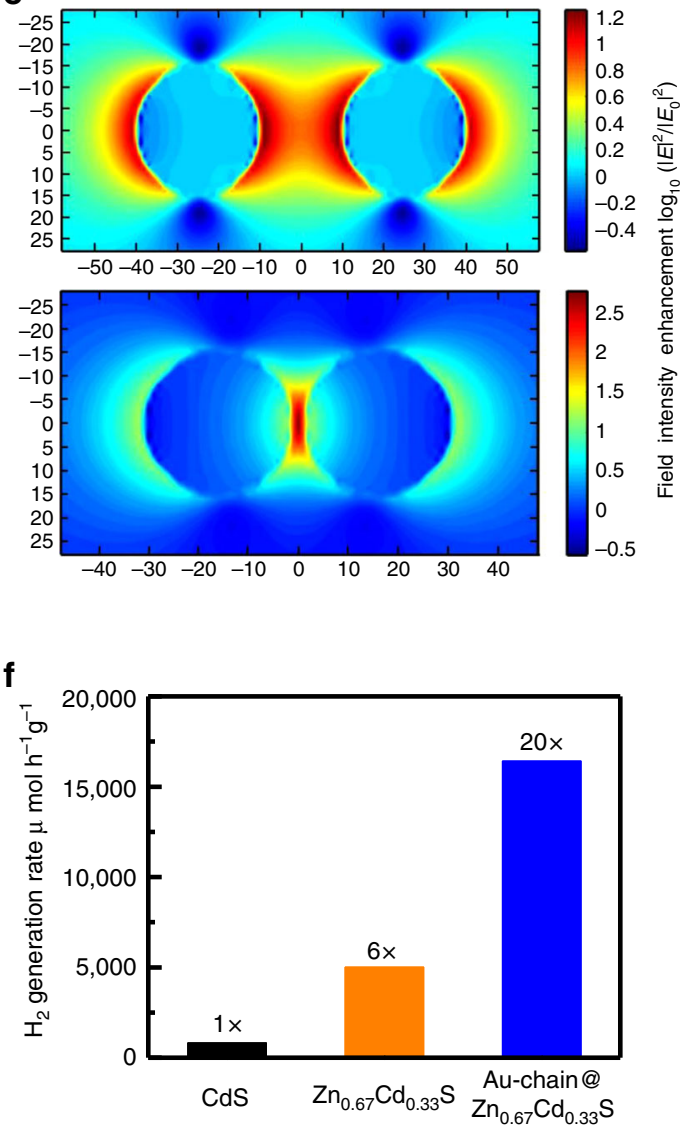

Fig. 1 Synthesis and physicochemical properties of photocatalysts. a Schematic illustration of the preparation process of $A u-c h a i n @ Z n_{0.67} C d_{0.33} S . b T_{1}$ and SAED patterns (inset), c HRTEM image, and d HAADF and EDXS mapping images of Au-chain@Z $\mathrm{n}_{0.67} \mathrm{Cd}_{0.33} \mathrm{~S}$. e FDTD simulation of the near-field distributions of isolated and coupled nanoparticles excited by visible light. f Photocatalytic $\mathrm{H}_{2}$ evolution activity of commercial $\mathrm{CdS}$, pure $\mathrm{Zn}_{0.67} \mathrm{Cd}_{0.33} \mathrm{~S}$ and Au-chain@Z $\mathrm{n}_{0.67} \mathrm{Cd}_{0.33} \mathrm{~S}$ under visible light irradiation $(\geq 420 \mathrm{~nm})$

noted that all these catalytic results are obtained in the absence of any additional metal or metal oxide as a cocatalyst on the surface of semiconductor. Under the optimized reaction conditions, the apparent quantum efficiency of Au-chain@ $\mathrm{Zn}_{0.67} \mathrm{Cd}_{0.33} \mathrm{~S}$ can even reach to $54.6 \%$ under $420 \mathrm{~nm}$ illumination (Supplementary Fig. 6). This efficiency is obviouly higher than most of literature results, and keeps leading in the tests free of cocatalysts (Supplementary Table 1). The high efficiency should attribute to the strongly coupled nanostructure of Au-nanochain embedded into the semiconductor.

Influence of the spatial arrangement of plasmonic metals. For systematic investigation of the dependence of the photocatalytic performance on the spatial arrangement of plasmonic Au, two other samples Au-iso@ $\mathrm{Zn}_{0.67} \mathrm{Cd}_{0.33} \mathrm{~S}$ (Au nanoparticles separately embedded into $\mathrm{Zn}_{0.67} \mathrm{Cd}_{0.33} \mathrm{~S}$, see Supplementary method and Supplementary Figs. 7 and 8) and Au-surf@ $\mathrm{Zn}_{0.67} \mathrm{Cd}_{0.33} \mathrm{~S}$ (Au nanoparticles post loaded on the surface of $\mathrm{Zn}_{0.67} \mathrm{Cd}_{0.33} \mathrm{~S}$, Supplementary method and Supplementary Figs. 7 and 9) were also prepared. Au-iso@ $\mathrm{Zn}_{0.67} \mathrm{Cd}_{0.33} \mathrm{~S}$ and pure $\mathrm{Zn}_{0.67} \mathrm{Cd}_{0.33} \mathrm{~S}$ were prepared with a hydrothermal method, which is the same as Au-chain@ $\mathrm{Zn}_{0.67} \mathrm{Cd}_{0.33} \mathrm{~S}$. Figure $2 \mathrm{a}$ shows the $\mathrm{X}$-ray diffraction (XRD) patterns of Au-chain@ $\mathrm{Zn}_{0.67} \mathrm{Cd}_{0.33} \mathrm{~S}$, $\mathrm{Au}$ iso@ $\mathrm{Zn}_{0.67} \mathrm{Cd}_{0.33} \mathrm{~S}, \quad \mathrm{Au}$-surf@ $\mathrm{Zn}_{0.67} \mathrm{Cd}_{0.33} \mathrm{~S}$ as well as pure $\mathrm{Zn}_{0.67} \mathrm{Cd}_{0.33} \mathrm{~S}$. All the samples exhibit six diffraction peaks at $2 \theta=25.1^{\circ}, 26.8^{\circ}, 28.4^{\circ}, 44.0^{\circ}, 48.1^{\circ}$, and $52.1^{\circ}$, which can be assigned to (100), (002), (101), (110), (103), and (112) planes of hexagonal wurtzite $\mathrm{Zn}_{0.67} \mathrm{Cd}_{0.33} \mathrm{~S}$ (JCPDS No. 40-0835) ${ }^{35}$. The diffraction peaks of Au nanoparticles cannot be detected in the XRD patterns, due to the low concentration and the highly dispersed state of $\mathrm{Au}$ nanoparticles in the samples. $\mathrm{N}_{2}$-adsorption results (Table 1) show that the specific surface areas of three Aucontaining samples are all at about $40 \mathrm{~m}^{2} \mathrm{~g}^{-1}$, which is just a little higher than that of pure $\mathrm{Zn}_{0.67} \mathrm{Cd}_{0.33} \mathrm{~S}\left(36.1 \mathrm{~m}^{2} \mathrm{~g}^{-1}\right)$. The isotherms (Supplementary Fig. 10) shows that all these samples are non-porous materials, which is consistent with that of TEM results.

Figure 2b, $c$ shows the X-ray photoelectron spectroscopy (XPS) of Au-chain@ $\mathrm{Zn}_{0.67} \mathrm{Cd}_{0.33} \mathrm{~S}$, Au-iso@ $\mathrm{Zn}_{0.67} \mathrm{Cd}_{0.33} \mathrm{~S}$, $\mathrm{Au}$ surf@ $\mathrm{Zn}_{0.67} \mathrm{Cd}_{0.33} \mathrm{~S}$, and pure $\mathrm{Zn}_{0.67} \mathrm{Cd}_{0.33} \mathrm{~S}$. All these four samples exhibit similar surface chemical state of $\mathrm{Cd}$ and $\mathrm{Zn}$. The surface $\mathrm{Zn} / \mathrm{Cd}$ ratios of these samples are all close to 2.0 (Table 1), which is nearly the same as the composition of the bulk. It should be noted that no signal of $\mathrm{Au}$ can be detected on the surface of Au-chain@ $\mathrm{Zn}_{0.67} \mathrm{Cd}_{0.33} \mathrm{~S}, \mathrm{Au}$-iso@ $\mathrm{Zn}_{0.67} \mathrm{Cd}_{0.33} \mathrm{~S}$ (Table 1 and Supplementary Fig. 11), confirming that Au nanoparticles in these two samples are embedded completely into the $\mathrm{Zn}_{0.67} \mathrm{Cd}_{0.33} \mathrm{~S}$ semiconductor.

Figure $3 \mathrm{a}$ shows the Raman spectroscopy of Auchain@ $\mathrm{Zn}_{0.67} \mathrm{Cd}_{0.33} \mathrm{~S}, \mathrm{Au}$-iso@ $\mathrm{Zn}_{0.67} \mathrm{Cd}_{0.33} \mathrm{~S}$, Au-surf@ $\mathrm{Zn}_{0.67} \mathrm{Cd}_{0.33} \mathrm{~S}$, and pure $\mathrm{Zn}_{0.67} \mathrm{Cd}_{0.33} \mathrm{~S}$. Two typical Raman scattering peaks of wurtzite $\mathrm{Zn}_{0.67} \mathrm{Cd}_{0.33} \mathrm{~S}$ can be observed in the spectroscopy, which are the first (1LO) and second (2LO) band of longitudinal optical (LO) phonon modes at 295 and $598 \mathrm{~cm}^{-1}$, respectively ${ }^{36}$. The intensity of Raman signals follows the order of Au-chain@ $\mathrm{Zn}_{0.67} \mathrm{Cd}_{0.33} \mathrm{~S}>\mathrm{Au}$ iso@ $\mathrm{Zn}_{0.67} \mathrm{Cd}_{0.33} \mathrm{~S}>\mathrm{Au}$-surf@ $\mathrm{Zn}_{0.67} \mathrm{Cd}_{0.33} \mathrm{~S}>\mathrm{Zn}_{0.67} \mathrm{Cd}_{0.33} \mathrm{~S}$. 

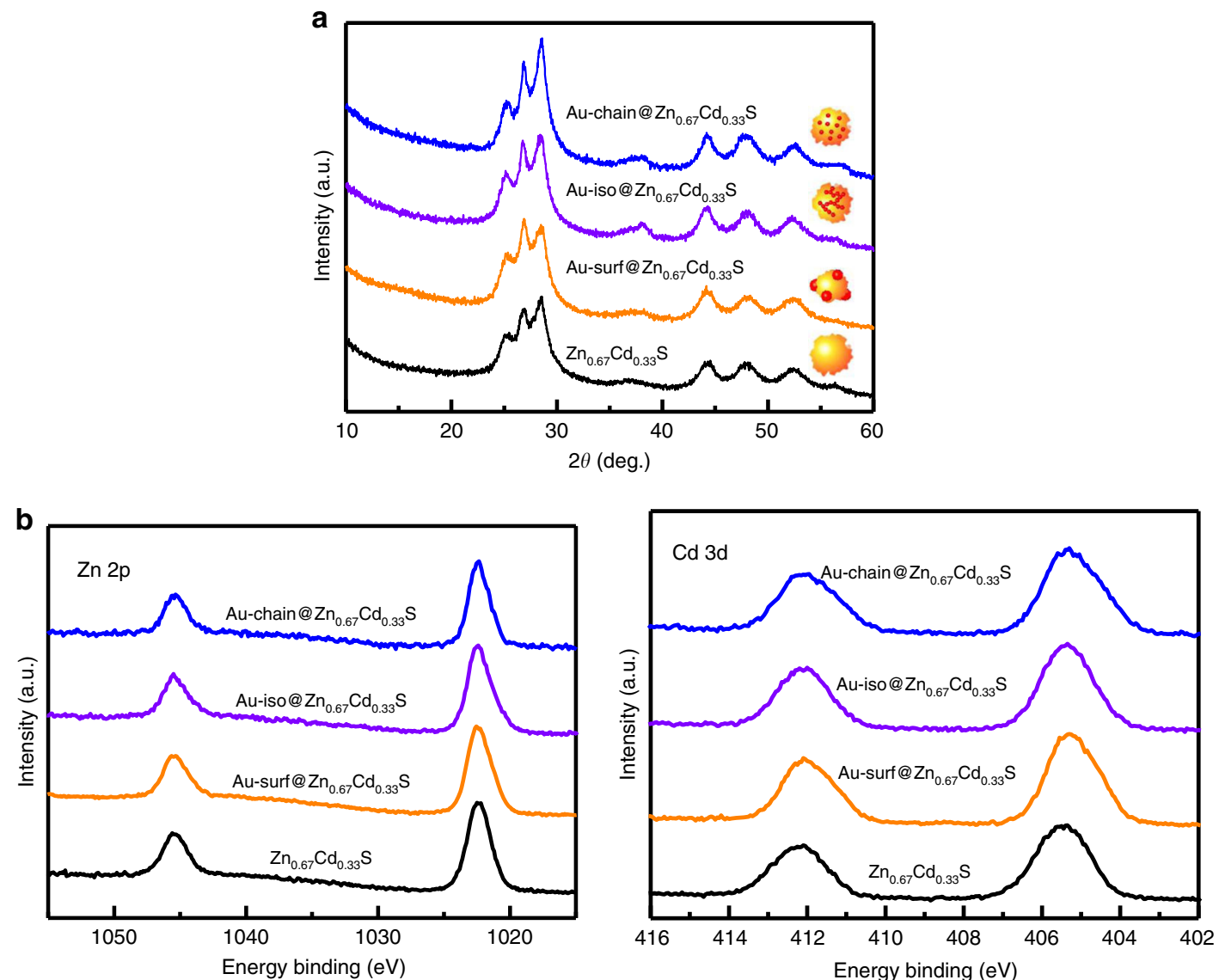

Fig. 2 Crystal structure and surface properties. a XRD patterns, b Zn $2 p$ and $C d 3 d$ XPS spectra of pure $\mathrm{Zn}_{0.67} \mathrm{Cd}_{0.33} \mathrm{~S}$ and $\mathrm{Au}_{\mathrm{u}} @ \mathrm{Zn}_{0.67} \mathrm{Cd} \mathrm{d}_{0.33} \mathrm{~S}$ with different spatial arrangement of Au nanoparticles

Table 1 Texture properties and the atom contents on the surface of various samples

\begin{tabular}{|c|c|c|c|c|c|}
\hline \multirow[t]{2}{*}{ Samples } & \multirow[t]{2}{*}{$S_{\text {BET }}\left(m^{2} g^{-1}\right)$} & \multicolumn{4}{|c|}{ XPS spectra results } \\
\hline & & Zn (at.\%) & Cd (at.\%) & Au (at.\%) & $\mathrm{Zn}: \mathrm{Cd}$ \\
\hline $\mathrm{Zn}_{0.67} \mathrm{Cd}_{0.33} \mathrm{~S}$ & 36.1 & 30.89 & 15.45 & 0 & $2.00: 1$ \\
\hline Au-surf@Zn $\mathrm{n}_{0.67} \mathrm{Cd}_{0.33} \mathrm{~S}$ & 40.1 & 30.47 & 14.87 & 0.14 & $2.05: 1$ \\
\hline Au-chain@Zn $n_{0.67} \mathrm{Cd}_{0.33} \mathrm{~S}$ & 40.9 & 31.72 & 15.81 & 0 & $2.01: 1$ \\
\hline
\end{tabular}

According to the principle of surface-enhanced Raman spectroscopy (SERS), the enhancement of signals relies on the received plasmoninduced local electromagnetic field from metal nanostructures ${ }^{37}$. $\mathrm{XRD}$ and XPS have shown that $\mathrm{Zn}_{0.67} \mathrm{Cd}_{0.33} \mathrm{~S}$ in all these samples possess nearly the same structure and surface properties. So, compared with pure $\mathrm{Zn}_{0.67} \mathrm{Cd}_{0.33} \mathrm{~S}$, the enhancement of Raman signals in Au-containing samples should be ascribed to the plasmoninduced local electromagnetic field of $\mathrm{Au}$ nanostructures. The field received by $\mathrm{Zn}_{0.67} \mathrm{Cd}_{0.33} \mathrm{~S}$ follows the order of embedded $\mathrm{Au}$ nanochain > embedded Au nanoparticles > surface Au nanoparticles.

$\mathrm{UV}$-vis spectra further confirm above results (Fig. 3b). In comparison with pure $\mathrm{Zn}_{0.67} \mathrm{Cd}_{0.33} \mathrm{~S}$, Au-containing samples show a red shift of absorption edge, which are due to the influence of LSPRs from Au nanostructure. This shift originates from the change of optical properties of $\mathrm{Zn}_{0.67} \mathrm{Cd}_{0.33} \mathrm{~S}$ affected by the electromagnetic effect of $\mathrm{Au}$ LSPR, while not a simple addition of absorption of $\mathrm{Zn}_{0.67} \mathrm{Cd}_{0.33} \mathrm{~S}$ and Au LSPR (Supplementary Figs. 1 and 12). Figure $3 \mathrm{~b}$ inset shows the difference spectra for the composite samples, which is obtained by substracting the $\mathrm{Zn}_{0.67} \mathrm{Cd}_{0.33} \mathrm{~S}$ spectrum from the composite spectra. Obviously, Au nanochains exhibit the greatest contribution to the increase of the optical absorption of the composite catalyst (Au-chain@ $\mathrm{Zn}_{0.67} \mathrm{Cd}_{0.33} \mathrm{~S}$ ) in the range of $430-480 \mathrm{~nm}$, followed by embedded $\mathrm{Au}$ nanoparticles (Au-iso@ $\mathrm{Zn}_{0.67} \mathrm{Cd}_{0.33} \mathrm{~S}$ ) and the ones on the surface (Au-surf@ $\mathrm{Zn}_{0.67} \mathrm{Cd}_{0.33} \mathrm{~S}$ ).

Both Raman and UV-vis results provide the experimental evidences that embedded $\mathrm{Au}$-nanochain has greatest impact on the excitation of $\mathrm{Zn}_{0.67} \mathrm{Cd}_{0.33} \mathrm{~S}$. It should originate from the electromagnetic properties of interacting $\mathrm{Au}$ nanoparticles in close mutual proximity. In brief, the interaction energy can be described with $V \propto p_{1} p_{2} / r^{3}$, where $p_{1}$ and $p_{2}$ are the magnitudes of the diple moments and $r$ is the inter particle distance ${ }^{38}$. This interaction energy is considerably stronger in the case of nearly adjacent Au nanoparticles ${ }^{39}$. FDTD simulations shown in Figs. 1c and $3 c$ further match the change of spectroscopy observed experimentally. The adjacent nanoparticle pairs showing a hot spot in the junction for incident polarization along the interparticle axis, where the strength of electromagnetic field at least one order of magnitudes in comparison with that of isolated particles. 

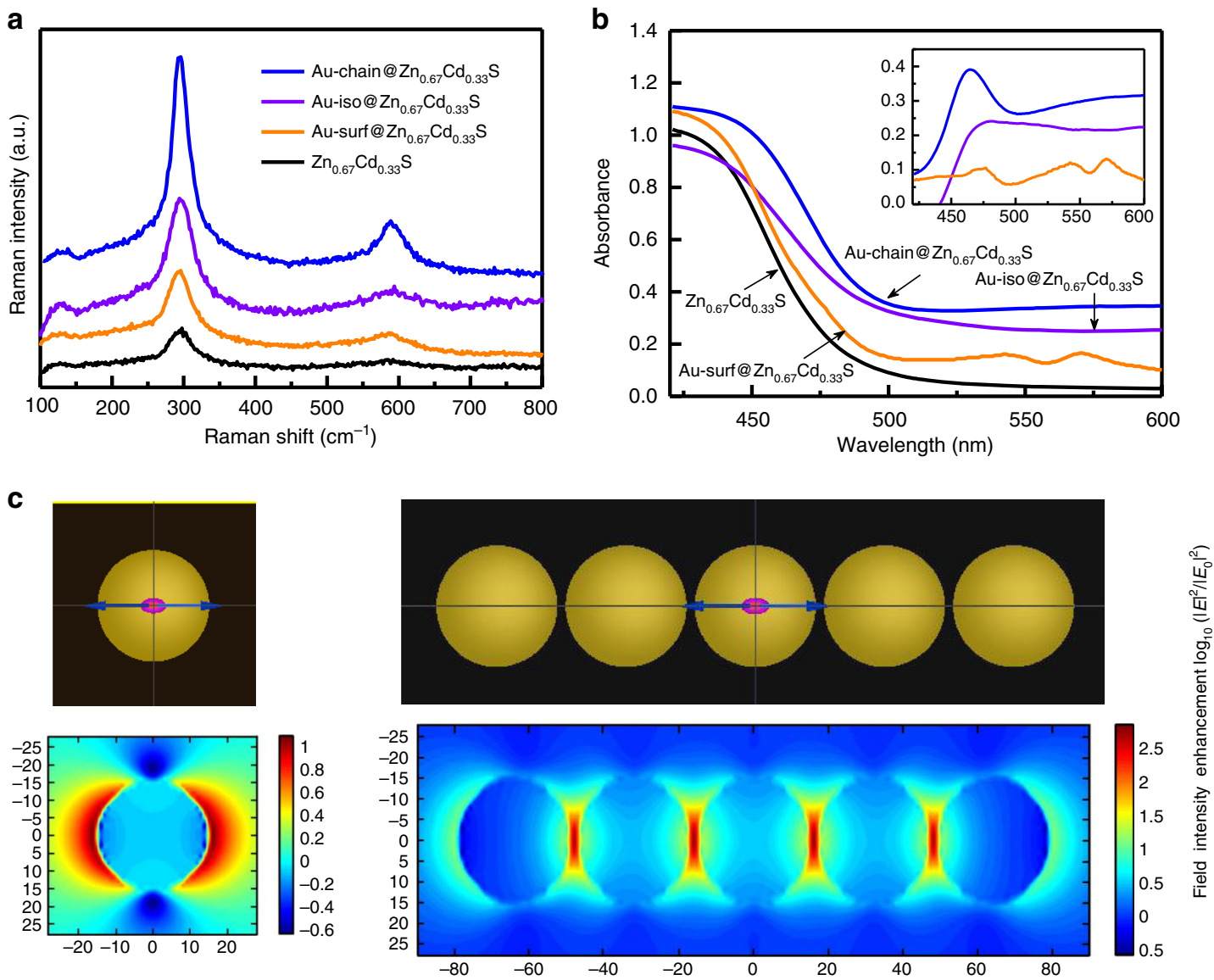

Fig. 3 Plasmon-induced local electromagnetic field effect. a Raman spectra. b UV-vis diffuses reflection spectra of pure $\mathrm{Zn}_{0.67} C d_{0.33} \mathrm{~S}$ and $\mathrm{Au} @ \mathrm{Zn}_{0.67} \mathrm{Cd}_{0.33} \mathrm{~S}$ with different spatial arrangement of Au nanoparticles. c FDTD simulation of the near-field distributions of single Au nanoparticle and five coupled Au nanoparticles

The enhancement of photocatalytic hydrogen evolution activity depended on the spatial arrangement of plasmonic Au nanostructure is shown in Fig. 4a. Compared with pure $\mathrm{Zn}_{0.67} \mathrm{Cd}_{0.33} \mathrm{~S}$ $\left(5020 \mu \mathrm{mol} \mathrm{h}^{-1} \mathrm{~g}^{-1}\right), \quad \mathrm{Au}$-surf@Zn $\mathrm{Zn}_{0.67} \mathrm{Cd}_{0.33} \mathrm{~S}$ and $\mathrm{Au}-$ iso@ $\mathrm{Zn}_{0.67} \mathrm{Cd}_{0.33} \mathrm{~S}$ enhance this activity to 8290 and 11,560 $\mu \mathrm{mol} \mathrm{h}{ }^{-1} \mathrm{~g}^{-1}$, respectively. The difference of these two samples is that isolated $\mathrm{Au}$ nanoparticles loaded on the surface for $\mathrm{Au}$ surf@ $\mathrm{Zn}_{0.67} \mathrm{Cd}_{0.33} \mathrm{~S}$ and embedded in the body for $\mathrm{Au}$ iso@ $\mathrm{Zn}_{0.67} \mathrm{Cd}_{0.33} \mathrm{~S}$. The different enhancement of photocatalytic activity is mainly due to the the proximity of $\mathrm{Zn}_{0.67} \mathrm{Cd}_{0.33} \mathrm{~S}$ to the electromagnetic field of plasmonic Au (Fig. 4b). Embedded structure facilitates the transfer of plasmonic energy from $\mathrm{Au}$ nanoparticle to the nearby $\mathrm{Zn}_{0.67} \mathrm{Cd}_{0.33} \mathrm{~S}$ semiconductor. All these activities are much lower than that of Au-chain@ $\mathrm{Zn}_{0.67} \mathrm{Cd}_{0.33} \mathrm{~S}$ $\left(16420 \mu \mathrm{mol} \mathrm{h}^{-1} \mathrm{~g}^{-1}\right)$. The contribution of Au-nanochain to the enhancement of photoconversion is about 3.5 times increase in comparison with that of isolated Au nanoparticles. Under the similar reaction conditions, the apparent quantum yield is $14.2 \%$, $19.3 \%, 28.7 \%$, and $43.5 \%$ for these four samples, respectively (Supplementary Fig. 6). The enhancements of these apparent quantum yields are consistent with the $\mathrm{H}_{2}$ evolution rate. The apparent quantum yield could be further optimized to $54.6 \%$ when increasing the amount of catalyst. The plasmon-coupled $\mathrm{Au}$ nanochain in Au-chain@ $\mathrm{Zn}_{0.67} \mathrm{Cd}_{0.33} \mathrm{~S}$ should play a crucial role for the enhancement of activity. In addition, it was observed that $\mathrm{Au}$-chain@ $\mathrm{Zn}_{0.67} \mathrm{Cd}_{0.33} \mathrm{~S}$ is also with a high stability in the reaction process (Supplementary Fig. 13). No changes were measured both in crystal structure and surface properties (XRD patterns and XPS spectra, Supplementary Figs. 14 and 15). It indicates that the increase of electromagnetic fields do not lower the stability of the semiconductor. All these evidences confirm that embedded Au-nanochain offers a opportunity to improve the photocatalytic performance of semiconductor photocatalysts via the increased electromagnetic energy field.

The intensity and proximity of electromagnetic fields essentially affect the rate of $\mathrm{e}^{-} / \mathrm{h}^{+}$formation in the $\mathrm{Zn}_{0.67} \mathrm{Cd}_{0.33} \mathrm{~S}$ semiconductor. Figure $4 \mathrm{c}$ shows the photoluminescence (PL) spectra of above four photocatalysts. It is known that photoexcited electron and hole recombine each other through several processes, such as direct band-to-band coupling and/or shallowly/ deeply trapped potential states ${ }^{40-42}$. The intensity of the spectra can reflect the amount of electrons recombined with holes under emission of photons. It can be observed that $\mathrm{Au}$ nanochain significantly improves the emission signal of $\mathrm{Zn}_{0.67} \mathrm{Cd}_{0.33} \mathrm{~S}$, followed by isolated $\mathrm{Au}$ nanoparticles. Time-resolved PL measurements (Fig. 4d) show that the intensity of $\mathrm{Au}$ chain@ $\mathrm{Zn}_{0.67} \mathrm{Cd}_{0.33} \mathrm{~S}$ decays much more slowly than that of other composite photocatalysts, and pure $\mathrm{Zn}_{0.67} \mathrm{Cd}_{0.33} \mathrm{~S}$, indicating a longer lifetime of electron-hole pairs in Au-chain@ $\mathrm{Zn}_{0.67} \mathrm{Cd}_{0.33} \mathrm{~S}$. This longer lifetime should be correlated with both the increasing amount of electron-hole pairs and the presence of surfacetrapped states. Fitting results of Cd $3 d$ XPS spectra show that there are certain amount of $\mathrm{Cd}$ species with low valent states on the surface of these four samples (Supplementary Fig. 16). Our previous work have shown that these Cd species act as the trap sites for photo-excited electrons and active sites for hydrogen evolution ${ }^{40,41}$. In this case, a broad emission signal in the range of $450-650 \mathrm{~nm}$ can be observed. No obvious shift among the signals 
a

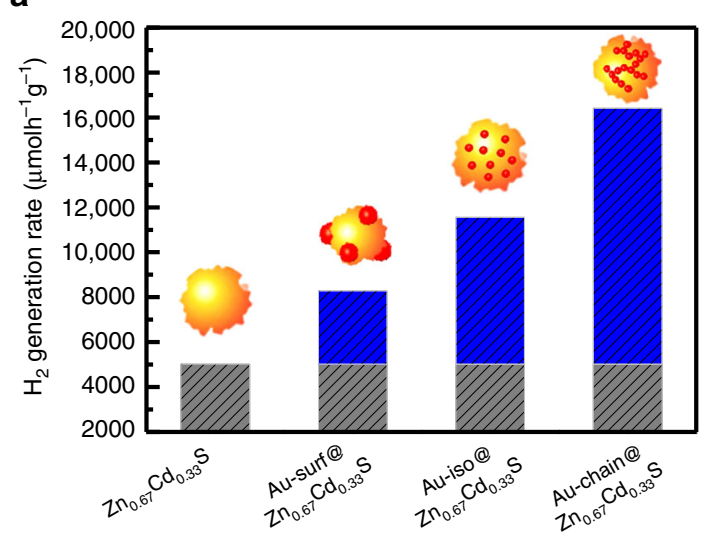

C

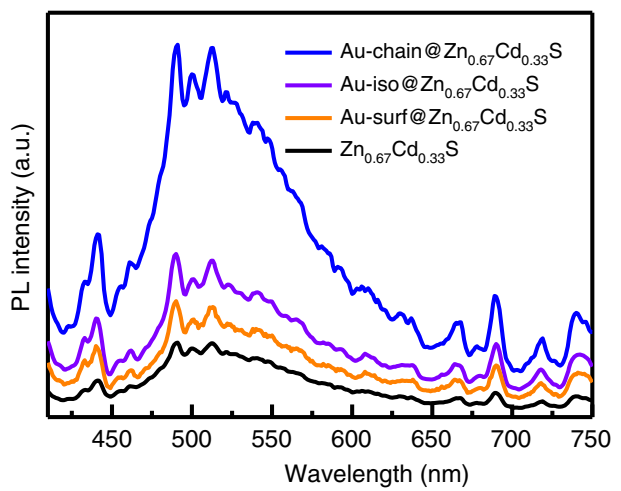

b

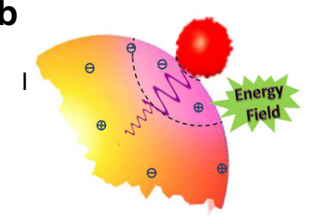

Au-surf $@ \mathrm{Zn}_{0.67} \mathrm{Cd}_{0.33} \mathrm{~S}$

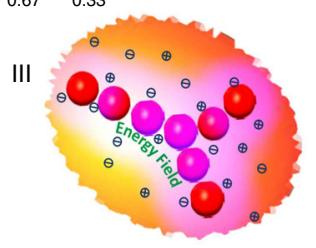

Au-chain $@ \mathrm{Zn}_{0.67} \mathrm{Cd}_{0.33} \mathrm{~S}$

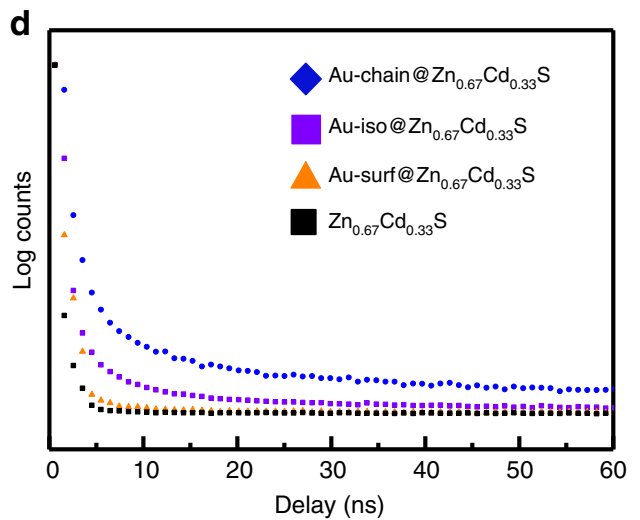

Fig. 4 Photocatalytic performance and mechanistic insights. a Photocatalytic $\mathrm{H}_{2}$ evolution activity of pure $\mathrm{Zn}_{0.67} \mathrm{Cd}_{0.33} \mathrm{~S}$ and $\mathrm{Au}_{\mathrm{u}} \mathrm{Zn} \mathrm{n}_{0.67} \mathrm{Cd}_{0.33} \mathrm{~S}$ with different spatial arrangement of Au nanoparticles under visible light irradiation ( $\geq 420 \mathrm{~nm}$ ); blue columns represent the enhancement promoted by plasmonic-Au nanostructures. b Illustration for the proximity of semiconductor to the electromagnetic fields of plasmonic Au nanoparticles. c Photoluminescence (PL) emission spectra of pure $\mathrm{Zn}_{0.67} \mathrm{Cd}_{0.33} \mathrm{~S}$ and different $\mathrm{Au} @ \mathrm{Zn}_{0.67} \mathrm{Cd}_{0.33} \mathrm{~S}$ samples, excitation wavelength: $390 \mathrm{~nm}$. $\mathbf{d} \mathrm{PL}$ lifetime decay of pure $\mathrm{Zn}_{0.67} \mathrm{Cd}_{0.33} \mathrm{~S}$ and different $\mathrm{Au} @ \mathrm{Zn}_{0.67} \mathrm{Cd}_{0.33} \mathrm{~S}$ samples, excitation wavelength: $400.8 \mathrm{~nm}$

of these samples should be mainly due to the similar crystal structure and surface properties of $\mathrm{Zn}_{0.67} \mathrm{Cd}_{0.33} \mathrm{~S}$ semiconductor in these four samples. This broad emission peak indicates the presence of multiple radiation processes of excited electrons, including the emission from the band edge and the surfacetrapped states. These trapped sites could play a more important role in sample of Au-chain@ $\mathrm{Zn}_{0.67} \mathrm{Cd}_{0.33} \mathrm{~S}$. With the increase of electron-hole pairs formation, much more electrons could be trapped by these sites and effectively extend the lifetime of electron-hole pairs.

\section{Discussion}

The $\mathrm{Au}$ nanoparticles in $\mathrm{Au}$-iso@ $\mathrm{Zn}_{0.67} \mathrm{Cd}_{0.33} \mathrm{~S}$ and $\mathrm{Au}$ chain@ $\mathrm{Zn}_{0.67} \mathrm{Cd}_{0.33} \mathrm{~S}$ are wrapped well by $\mathrm{Zn}_{0.67} \mathrm{Cd}_{0.33} \mathrm{~S}$ semiconductor. Little porous structure can be detected in these samples. So, the role of Au nanoparticles as a cocatalyst can be excluded. All the enhancements can be ascribed to the plasmonic effect of Au nanoparticles in the metal-semiconductor building blocks. In addition, the $\mathrm{Au}$ nanoparticles are protected by citric acid groups in the colloids aqueous solution and coupled with $L$-cysteine during the hydrothermal synthesis. There should be a non-conductive organic layer between Au nanoparticle and sulfide compound. It can be preliminarily verified by FT-IR measurement (Supplementary Fig. 17). This structure is suitable for the energy transfer from plasmonic Au to the semiconductor and could avoid the quenching of charge carriers on the surface of $\mathrm{Au}$ nanoparticles.
Combining all the above results, it can be concluded that the proximity and the spatial arrangement of plasmonic Au are two important factors affecting the photocatalytic performance. Firstly, the structure of embedding Au into the body of semiconductor effectively improves the proximity, facilitating the transfer and maximizing the use of electromagnetic energy from plasmonic $\mathrm{Au}$ to semiconductor (Fig. 4b). As for the isolated $\mathrm{Au}$ nanoparticle, theoretical simulation reported by Thomann et al. over $50 \mathrm{~nm} \mathrm{Au} \mathrm{nanoparticles} \mathrm{showed} \mathrm{that} \mathrm{the}$ strength of electromagnetic field vary little whether the nanoparticle locates on the top or the bottom of the semiconductor $^{43}$. So, shorter distance between the semiconductor and plasmonic Au could realize more energy transfer. Secondly, the strongly coupled nanostructure of $\mathrm{Au}$ nanochain shows stronger capability of improving local electromagnetic energy field. The collective excitation of plasmonic metal facilitate much more plasmonic energy transfer from metal to the semiconducor. This energy enhances the formation rate and lifetime of $\mathrm{e}^{-} / \mathrm{h}^{+}$pairs. Combined with quantum efficiency and stability measurements, it can further confirm that the coupled metal nanoparticles lead to an increase in lifetime of photo-excited electron-hole pairs. The significant enhancement of photocatalytic activity should origin from the collective behavior of these coupled metal nanoparticles, which is quite different from simple plasmonic effect of the isolated one. All these results show that embedding the plasmon-coupled metal nanostructure into semiconductor would be an effective strategy to fully take advantage of plasmonic energy. 
It is known that $\mathrm{Au}$ nanochain is only one simple nanostructure with plasmon-enhancement effect. Considering a great deal of coupled metallic nanostructures has been reported in physics and nanoscience area, embedding different kinds of coupled nanostructure into semiconductor could further optimize the efficiency of photocatalysts. In addition, recombination of photoexcited electron-hole pairs is present in all semiconductor materials. Considering this recombination, the $\mathrm{Au}$ nanoparticle closer to the surface could favorite more charge carriers been utilized. Therefore, there should be an optimized depth of $\mathrm{Au}$ nanoparticle due to the balance of energy utilization (electron-hole pair formation) and charge carriers recombination. It correlates with both the nature of semiconductors and their crystallizations. Further work is still needed on the investigation of various kinds of coupled plasmonic metal nanostructure and optimizing the placement of these metal nanoparticles in the semiconductors.

In summary, Au-nanochain with strongly coupled plasmonic nanostructure was demonstrated to be an effective building block to enhance the photocatalytic performance of nearby semiconductor. The chain structure possesses junction or short distance between adjacent nanoparticles, which gives rise to highly intense and localized electromagnetic fields. The embedded structure facilitates the nearby semiconductor to capture the strong field. The maximun control and utilization of this electromagnetic field significantly improve the formation of electron-hole pairs in the semiconductor photocatalysts, and ultimately enhance photocatalytic hydrogen evolution. The construction of coupled-metal nanostructures within the semiconductors represents an efficient way to enhance the solar energy conversion efficiency.

\section{Methods}

All chemicals were analytic grade reagents and used without further purification. Purified water was used in all of the experiments.

Preparation of Au colloids. Au colloids were prepared by a sodium citrate reduction method. Typically, an aqueous solution of $\mathrm{HAuCl}_{4}(0.25 \mathrm{mM}, 100 \mathrm{~mL})$ was heated to boiling, followed by the rapid addition of sodium citrate solution $(0.5 \mathrm{M}, 200 \mu \mathrm{L})$. The solution was kept boiling for another $15 \mathrm{~min}$, producing a stable and deep-red dispersion of Au nanoparticles with an average diameter of about $15 \mathrm{~nm}$ (see in Supplementary Fig. 1). The citrate-protected Au-colloids suspension (denoted as $\mathrm{Au}-\mathrm{Cit}$ ) was then cooled to room temperature for next use.

\section{Preparation of $A u$ nanochain embedded into $\mathbf{Z n}_{0.67} \mathbf{C d}_{0.33} \mathbf{S}$ (denoted as $A u$ -} chain@ $\left.\mathbf{Z n}_{\mathbf{0 . 6 7}} \mathbf{C d}_{\mathbf{0 . 3 3}} \mathbf{S}\right)$. Au-chain@ $\mathrm{Zn}_{0.67} \mathrm{Cd}_{0.33} \mathrm{~S}$ was prepared using a cysteineassisted hydrothermal approach. Briefly, $100 \mathrm{~mL} \mathrm{~L}$-cysteine solution (Cys, $60 \mathrm{mM}$ ) was mixed with $\mathrm{Zn}\left(\mathrm{NO}_{3}\right)_{2}$ and $\mathrm{Cd}\left(\mathrm{NO}_{3}\right)_{2}$ in a 1:0.5 molar ratio of $\mathrm{Cys}$ to $\mathrm{Zn}^{2+} / \mathrm{Cd}^{2+}$. The mixture was stirred for $30 \mathrm{~min}$ to form the stable complexes of cysteine- $\mathrm{Zn}^{2+}$ / $\mathrm{Cd}^{2+}$. Then Au-Cit colloids $(0.25 \mathrm{mM}, 1 \mathrm{~mL})$ was added to the freshly prepared cysteine- $\mathrm{Zn}^{2+} / \mathrm{Cd}^{2+}$ solution under vigorous stirring for $30 \mathrm{~min}$, leading to a complete coupling between amine group of Cys and $\mathrm{Au}$ nanoparticles surface. Subsequently, the cysteine- $\mathrm{Zn}^{2+} / \mathrm{Cd}^{2+}$-coupled Au colloids were diluted to a total volume of $70 \mathrm{~mL}$ with deionized water and transferred into $100 \mathrm{~mL}$ Teflonlined stainless-steel autoclaves. The autoclaves were maintained at $130^{\circ} \mathrm{C}$ for $6 \mathrm{~h}$ and then cooled to room temperature naturally. The products were filtered and washed with distilled water to remove remaining ions and impurities. After that, the products were fully dried at $80^{\circ} \mathrm{C}$ in an oven to obtain the final product. The amount of $\mathrm{Au}$ in the $\mathrm{Au} @ \mathrm{Zn}_{0.67} \mathrm{Cd}_{0.33} \mathrm{~S}$ composites was controlled by the amount of Au-Cit colloids in the synthesis process. The stoichiometric ratio is controlled at about $1.0 \mathrm{wt} \%$. As a reference, pure $\mathrm{Zn}_{0.67} \mathrm{Cd}_{0.33} \mathrm{~S}$ solid solution was prepared with the same procedure as described above without adding Au-Cit colloids.

Characterization methods. TEM images were taken on JEM-2100F with an accelerating voltage of $200 \mathrm{kV}$ equipped with an energy-dispersive spectroscopy analyzer. Powder X-ray diffraction (XRD) patterns were recorded on a Rigaku $\mathrm{X}$-ray diffractometer using $\mathrm{Cu} \mathrm{Ka}$ radiation $(\lambda=1.5418 \AA)$. UV-vis diffused reflectance spectra of the samples were obtained from UV-vis-NIR spectrophotometer (Shimadzu-3600). XPS was performed on a Thermo ESCA LAB 250 system with $\mathrm{MgKa}$ source $(1254.6 \mathrm{eV})$. The binding energies were calibrated using $\mathrm{C} 1 \mathrm{~s}$ peak at $284.6 \mathrm{eV}$ as standard. Raman spectra was measured at room temperature equipped with an Ar laser working at wavelengths of $532 \mathrm{~nm}$ (LabRAM HR Evolution, Horiba). The PL measurement was carried out on the FLS920 (Edinburgh Instrument) at room temperature using the excitation wavelength of $390 \mathrm{~nm}$.

FDTD simulation. The near-field distributions of Au nanoparticles were simulated by the three-dimensional FDTD method. The TF/SF source was used in simulation. The incident wavelength is $520 \mathrm{~nm}$. The grid spacing is $0.5 \mathrm{~nm}$. The radius of gold nanosphere is $7.5 \mathrm{~nm}$. The dielectric properties for gold are taken from ref. ${ }^{44}$. The background index is set to 1.0 .

Photocatalytic reaction. The photocatalytic $\mathrm{H}_{2}$ evolution reactions were carried out in a flowing gas diffluent system. The catalyst powder $(0.1 \mathrm{~g})$ was dispersed by a magnetic stirrer in $100 \mathrm{~mL}$ of $0.35 \mathrm{M} \mathrm{Na}_{2} \mathrm{~S}$ and $0.25 \mathrm{M} \mathrm{Na}_{2} \mathrm{SO}_{3}$ aqueous solution in a reaction cell made of Pyrex glass. The reaction temperature was maintained at $15^{\circ} \mathrm{C}$. The reaction solution was evacuated $30 \mathrm{~min}$ to ensure complete air removal prior to light irradiation. Magnetic stirring was used to keep the photocatalyst particles in a suspension state. A $300 \mathrm{~W}$ Xe-lamp with a cutoff filter was employed for visible-light $(\lambda \geq 420 \mathrm{~nm})$ irradiation. The amounts of evolved $\mathrm{H}_{2}$ was determined by an online gas chromatograph (GC 8 A, TCD) equipped with a $4 \mathrm{~m} 5 \mathrm{~A}$ molecular sieve columns and Ar as carrier gas.

The apparent quantum efficiency was measured under the same photocatalytic reaction except for the wavelength of irradiation light. The apparent quantum efficiency of different amounts of photocatalysts in one continuous reaction under visible light with different wavelengths of $420,450,500,550,600 \mathrm{~nm}$ were measured. Apparent quantum efficiency at different wavelengths was calculated by the following function. The band-pass and cutoff filters and a photodiode were used in measurement.

$$
\begin{aligned}
\operatorname{AQE}(\%) & =\frac{\text { Number of reacted electrons }}{\text { Total number of incident photons }} \times 100 \\
& =\frac{2 \times \text { The number of evoluted } \mathrm{H}_{2} \text { molecules }}{\text { Total number of incident photons }} \times 100
\end{aligned}
$$

\section{Data availability}

The data that support the findings of this study are available within the article and its Supplementary Information, and all data are available from the corresponding authors upon request.

Received: 10 May 2019; Accepted: 6 October 2019; Published online: 29 October 2019

\section{References}

1. Schultz, D. M. \& Yoon, T. P. Solar synthesis: prospects in visible light photocatalysis. Science 343, 1239176 (2014)

2. Ning, C.-Z., Dou, L. \& Yang, P. Bandgap engineering in semiconductor alloy nanomaterials with widely tunable compositions. Nat. Rev. Mater. 2, 17070 (2017).

3. Wang, W., Chen, J., Li, C. \& Tian, W. Achieving solar overall water splitting with hybrid photosystems of photosystem II and artificial photocatalysts. Nat. Commun. 5, 4647 (2014).

4. Maeda, K. et al. Photocatalyst releasing hydrogen from water. Nature 440, 295 (2006).

5. Martin, D. J., Reardon, P. J., Moniz, S. J. \& Tang, J. Visible light-driven pure water splitting by a nature-inspired organic semiconductor-based system. $J$. Am. Chem. Soc. 136, 12568-12571 (2014).

6. Wang, S., Guan, B. Y. \& Lou, X. W. D. Construction of $\mathrm{ZnIn}_{2} \mathrm{~S}_{4}-\operatorname{In}_{2} \mathrm{O}_{3}$ hierarchical tubular heterostructures for efficient $\mathrm{CO}_{2}$ photoreduction. J. Am. Chem. Soc. 140, 5037-5040 (2018).

7. Sivula, K. \& van de Krol, R. Semiconducting materials for photoelectrochemical energy conversion. Nat. Rev. Mater. 1, 15010 (2016).

8. Linic, S., Christopher, P. \& Ingram, D. B. Plasmonic-metal nanostructures for efficient conversion of solar to chemical energy. Nat. Mater. 10, 911-921 (2011).

9. Jia, C. et al. Interface-engineered plasmonics in metal/semiconductor heterostructures. Adv. Energy Mater. 6, 1600431 (2016).

10. Cushing, S. K. et al. Photocatalytic activity enhanced by plasmonic resonant energy transfer from metal to semiconductor. J. Am. Chem. Soc. 134, 15033-15041 (2012)

11. Ingram, D. B. \& Linic, S. Water splitting on composite plasmonic-metal/ semiconductor photoelectrodes: evidence for selective plasmon-induced formation of charge carriers near the semiconductor surface. J. Am. Chem. Soc. 133, 5202-5205 (2011). 
12. Li, J. et al. Plasmon-induced photonic and energy-transfer enhancement of solar water splitting by a hematite nanorod array. Nat. Commun. 4, 2651 (2013).

13. Zhang, P., Wang, T. \& Gong, J. Mechanistic understanding of the plasmonic enhancement for solar water splitting. Adv. Mater. 27, 5328-5342 (2015).

14. Xu, J. et al. CdS core-Au plasmonic satellites nanostructure enhanced photocatalytic hydrogen evolution reaction. Nano Energy 49, 363-371 (2018).

15. Boerigter, C., Campana, R., Morabito, M. \& Linic, S. Evidence and implications of direct charge excitation as the dominant mechanism in plasmon-mediated photocatalysis. Nat. Commun. 7, 10545 (2016).

16. Scholl, J. A., Koh, A. L. \& Dionne, J. A. Quantum plasmon resonances of individual metallic nanoparticles. Nature 483, 421 (2012).

17. Zhao, M. et al. Fabricating a Au@ $\mathrm{TiO}_{2}$ plasmonic system to elucidate alkaliinduced enhancement of photocatalytic $\mathrm{H}_{2}$ evolution: surface potential shift or methanol oxidation acceleration? ACS Catal. 8, 4266-4277 (2018).

18. Lee, J. B., Choi, S., Kim, J. \& Nam, Y. S. Plasmonically-assisted nanoarchitectures for solar water splitting: obstacles and breakthroughs. Nano Today 16, 61-81 (2017).

19. Li, J. et al. Plasmon-induced resonance energy transfer for solar energy conversion. Nat. Photonics 9, 601-607 (2015).

20. Long, R., Li, Y., Song, L. \& Xiong, Y. Coupling solar energy into reactions: materials design for surface plasmon-mediated catalysis. Small 11, 3873-3889 (2015).

21. Tan, S. et al. Plasmonic coupling at a metal/semiconductor interface. Nat. Photonics 11, 806-812 (2017).

22. Li, J. et al. $\mathrm{Ag} @ \mathrm{Cu}_{2} \mathrm{O}$ core-shell nanoparticles as visible-light plasmonic photocatalysts. ACS Catal. 3, 47-51 (2013).

23. Yang, T.-T. et al. Interfacial charge carrier dynamics in core-shell Au-CdS nanocrystals. J. Phys. Chem. C 114, 11414-11420 (2010).

24. Chen, J., Dong, C.-L., Du, Y., Zhao, D. \& Shen, S. Nanogap engineered plasmon-enhancement in photocatalytic solar hydrogen conversion. $A d v$. Mater. Interfaces 2, 1500280 (2015).

25. Thimsen, E., Le Formal, F., Gratzel, M. \& Warren, S. C. Influence of plasmonic Au nanoparticles on the photoactivity of $\mathrm{Fe}_{2} \mathrm{O}_{3}$ electrodes for water splitting. Nano Lett. 11, 35-43 (2011).

26. Yang, J. L. et al. In situ SERS study of surface plasmon resonance enhanced photocatalytic reactions using bifunctional Au@CdS core-shell nanocomposites. Nanoscale 9, 6254-6258 (2017).

27. Naya, S., Niwa, T., Kume, T. \& Tada, H. Visible-light-induced electron transport from small to large nanoparticles in bimodal gold nanoparticleloaded titanium(IV) oxide. Angew. Chem. Int. Ed. 53, 7305-7309 (2014).

28. Tan, C. F. et al. Inverse stellation of $\mathrm{CuAu}-\mathrm{ZnO}$ multimetallic-semiconductor nanostartube for plasmon-enhanced photocatalysis. ACS Nano 12, 4512-4520 (2018).

29. Dutta, S. K., Mehetor, S. K. \& Pradhan, N. Metal semiconductor heterostructures for photocatalytic conversion of light energy. J. Phys. Chem. Lett. 6, 936-944 (2015).

30. Jiang, W. et al. Integration of multiple plasmonic and co-catalyst nanostructures on $\mathrm{TiO}_{2}$ nanosheets for visible-near-infrared photocatalytic hydrogen evolution. Small 12, 1640-1648 (2016).

31. Linic, S., Christopher, P., Xin, H. \& Marimuthu, A. Catalytic and photocatalytic transformations on metal nanoparticles with targeted geometric and plasmonic properties. Acc. Chem. Res. 46, 1890-1899 (2013).

32. Zhu, C. et al. A hierarchically ordered array of silver-nanorod bundles for surface-enhanced raman scattering detection of phenolic pollutants. Adv. Mater. 28, 4871-4876 (2016)

33. Lange, H. et al. Tunable plasmon coupling in distance-controlled gold nanoparticles. Langmuir 28, 8862-8866 (2012).

34. Ingram, D. B., Christopher, P., Bauer, J. L. \& Linic, S. Predictive model for the design of plasmonic metal/semiconductor composite photocatalysts. ACS Catal. 1, 1441-1447 (2011)

35. Liu, M., Wang, L., Lu, G., Yao, X. \& Guo, L. Twins in $\mathrm{Cd}_{1-\mathrm{x}} \mathrm{Zn}_{\mathrm{x}} \mathrm{S}$ solid solution: highly efficient photocatalyst for hydrogen generation from water. Energy Environ. Sci. 4, 1372 (2011)

36. Fan, H. M. et al. Orientation-dependent Raman spectroscopy of single wurtzite CdS nanowires. J. Phys. Chem. C 112, 1865-1870 (2008).

37. Cao, L., Nabet, B. \& Spanier, J. E. Enhanced Raman scattering from individual semiconductor nanocones and nanowires. Phys. Rev. Lett. 96, 157402 (2006).
38. Halas, N. J., Lal, S., Chang, W. S., Link, S. \& Nordlander, P. Plasmons in strongly coupled metallic nanostructures. Chem. Rev. 111, 3913-3961 (2011).

39. Seh, Z. W. et al. Janus Au- $\mathrm{TiO}_{2}$ photocatalysts with strong localization of plasmonic near-fields for efficient visible-light hydrogen generation. Adv. Mater. 24, 2310-2314 (2012).

40. Yu, G., Geng, L., Wu, S., Yan, W. \& Liu, G. Highly-efficient cocatalyst-free $\mathrm{H}_{2-}$ evolution over silica-supported CdS nanoparticle photocatalysts under visible light. Chem. Commun. 51, 10676-10679 (2015).

41. Yu, G. et al. A highly active cocatalyst-free semiconductor photocatalyst for visible-light-driven hydrogen evolution: synergistic effect of surface defects and spatial bandgap engineering. J. Mater. Chem. A 4, 13803-13808 (2016).

42. Warren, S. C. \& Thimsen, E. Plasmonic solar water splitting. Energy Environ Sci. 5, 5133-5146 (2012).

43. Thomann, I. et al. Plasmon enhanced solar-to-fuel energy conversion. Nano Lett. 11, 3440-3446 (2011).

44. Johnson, P. B. \& Christy, R. W. Optical constants of the noble metals. Phys. Rev. B 6, 4370-4379 (1972).

\section{Acknowledgements}

The authors acknowledge support from the National Natural Science Foundation of China $(21473073,11304164,21972053)$, "13th Five-Year" science and technology research of the Education Department of Jilin Province (2016403), the Development Project of Science and Technology of Jilin Province (20170101171JC, 20180201068SF), the Open Project of State Key Laboratory of Inorganic Synthesis and Preparative Chemistry (201703) and the Fundamental Research Funds for the Central Universities.

\section{Author contributions}

G.Y. and G.L. designed the experiment and performed the measurements and data analysis. J.Q. contributed to the theoretical simulation. B.Z. contributed to photocatalytic test. W.Z and W.Y. contributed to the optical measurement. G.Y., P.Z. and G.L. contributed to the discussion and the writing of the manuscript. All authors commented on the manuscript.

\section{Competing interests}

The authors declare no competing interests.

\section{Additional information}

Supplementary information is available for this paper at https://doi.org/10.1038/s41467019-12853-8.

Correspondence and requests for materials should be addressed to G.L.

Peer review information Nature Communications thanks the anonymous reveiwers for their contributions to the peer review of this work. Peer review reports are available.

Reprints and permission information is available at http://www.nature.com/reprints

Publisher's note Springer Nature remains neutral with regard to jurisdictional claims in published maps and institutional affiliations.

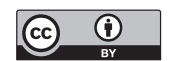

Open Access This article is licensed under a Creative Commons Attribution 4.0 International License, which permits use, sharing adaptation, distribution and reproduction in any medium or format, as long as you give appropriate credit to the original author(s) and the source, provide a link to the Creative Commons license, and indicate if changes were made. The images or other third party material in this article are included in the article's Creative Commons license, unless indicated otherwise in a credit line to the material. If material is not included in the article's Creative Commons license and your intended use is not permitted by statutory regulation or exceeds the permitted use, you will need to obtain permission directly from the copyright holder. To view a copy of this license, visit http://creativecommons.org/ licenses/by/4.0/.

(C) The Author(s) 2019 